\title{
Review
}

Journal of Innate

Immunity
J Innate Immun 2012;4:454-462

DOI: $\underline{10.1159 / 000334576}$
Received: September 12, 2011

Accepted after revision: October 19, 2011 Published online: February 1, 2012

\section{Uveal Melanoma: The Inflammatory Microenvironment}

\author{
Inge H.G. Bronkhorst Martine J. Jager \\ Department of Ophthalmology, Leiden University Medical Center, Leiden, The Netherlands
}

\author{
Key Words \\ Uveal melanoma $\cdot$ Inflammation $\cdot$ Macrophages
}

\begin{abstract}
Uveal melanoma is a highly malignant intraocular tumor with quite homogeneous tumor tissue and a diffuse leukocytic infiltration. In contrast with many other malignancies, the presence of infiltrating macrophages and T cells is associated with a poor prognosis rather than a good one. The clear link between inflammation and cancer in this malignancy provides a paradigm for macrophage plasticity and function. Macrophages in uveal melanoma have an M2-like phenotype and are associated with the loss of one specific chromosome - monosomy 3 . The central players involved in this process and discussed in this review include macrophages, T lymphocytes, chemokines and cytokines, including the macrophage-attraction molecules. When a tumor acquires the ability to release significant amounts of macrophage-attraction molecules it causes the expansion of a population of myeloid immature cells that may not only help the tumor to suppress immune reactions but also aid in the construction of new blood vessels for tumor growth. A better understanding of the molecular basis of a local myelomonocytic cell population will bring a better understanding of the immunopathology of this disease and will lead to therapeutic interventions in uveal melanoma. This review focuses on the roles of the local inflammatory microenvironment in the development and progression of uveal melanoma.
\end{abstract}

Copyright ๑ 2012 S. Karger AG, Basel
(C) 2012 S. Karger AG, Basel

$1662-811 X / 12 / 0046-0454 \$ 38.00 / 0$

Fax +41613061234

E-Mail karger@karger.ch

www.karger.com
Accessible online at:

www.karger.com/jin

\section{Introduction}

Uveal melanoma is the most common primary intraocular tumor in adults with an incidence of 5.1 per million [1] and is a tumor that metastasizes easily. Uveal melanoma arises in the iris or in the more posterior parts of the eye, i.e. the ciliary body or the choroid. Metastases will develop in about $50 \%$ of patients with large tumors that need enucleation [2]. Metastases have a predilection for the liver and once they have developed, median survival is about 1 year [3]. There are many therapeutic modalities for the intraocular uveal melanoma which aim at conserving the eye and vision, but there is no effective cure for metastatic disease $[4,5]$. Unfortunately, survival remained unchanged between 1973 and 2008 [1].

The eye is an immune-privileged site, but inflammation can be present within the established ocular tumor microenvironment [6]. Inflammation was recently established as the seventh hallmark of cancer [7]. Cancer cells may exploit immune evasion to survive and expand [8]. Uveal melanomas are quite homogeneous without much stromal tissue and may therefore themselves be the major influence on the influx of tumor-infiltrating leukocytes (TIL). We look at inflammatory characteristics of the uveal melanoma microenvironment as this offers opportunities for the development of therapeutic agents. As cancer cells may depend on inflammatory cytokines for their growth, understanding inflammation-related processes that play a role in the outgrowth of uveal melanoma and its metastases may lead to new treatments. 


\section{Tumor Microenvironment}

Inflammatory infiltrates play a critical role during different developmental stages of most malignancies and their progression. It is important to look at the various cells present in the tumor microenvironment as the interplay between these cells can affect both tumor growth and macrophage function. With regard to uveal melanoma, this infiltrate consists of a heterogeneous group of cells. The classifications of immune cells in situ are based on cell surface markers and therefore illustrate phenotypic rather than functional qualities. A large immunohistochemical study showed that 134 out of 1,078 tumors contained a lymphocytic infiltrate (100 or more lymphocytes per 20 high-power $(\times 400)$ microscopic fields) [9]. A second study of 27 tumors showed that lymphocyte infiltration is variable when tumor suspensions were analyzed by flow cytometry and a substantial proportion of TIL were CD8+ T cells, with some CD4+ T cells [10]. These subpopulations were respectively named $\mathrm{T}$ suppressor/cytotoxic $\mathrm{T}$ lymphocytes (CTL) and helper $\mathrm{T}$ cells, but they were not functionally assessed. Natural killer (NK) cells are lacking in primary uveal melanomas [11] and B cells are rare [12]. More recently, Foxp3+ regulatory $\mathrm{T}$ cells (Treg) were found to be present in 12-24\% of uveal melanomas $[13,14]$. These are a specialized subpopulation of $\mathrm{T}$ cells which suppress the activation of the immune system.

Not only T cells but also macrophages, which can be identified because they express CD68+, are commonly present in uveal melanoma and are referred to as tumorassociated macrophages (TAMs). Their number is higher in tumors with epithelioid cells, increased microvascular density (MVD) and large tumor size, all of which are markers of increased malignancy [15]. In an immunohistochemical study of 24 tumors, the presence of a T lymphocyte infiltrate was positively correlated with an increased density of CD11b macrophages, both of which were related to human leukocyte antigen (HLA) expression [11]. This increased expression of HLA class I as well as HLA class II occurred more frequently in epithelioid cell type tumors. In a study of 103 uveal melanomas, cells of the monocyte/macrophage lineage, rather than $\mathrm{T}$ cells, were the predominant group of TIL [16]. Two types of TAMs can be identified: M2 and M1 macrophages. The former generally have less antigen presentation or tumoricidal capacity, dampen $\mathrm{T}$ cell responses and show a high expression of angiogenic factors [e.g. vascular endothelial growth factor (VEGF)]. On the other hand, classically-activated M1 macrophages kill cancer cells and elicit tumor-destructive reactions centered on blood vessels [17]. In uveal melanoma, the macrophages within the tumor almost all display the same phenotype, as determined by immunofluorescence histochemistry with monoclonal antibodies against CD68 and CD163, which qualifies them as the M2 type [18].

\section{Prognostic Relevance}

A wide range of prognostic parameters have been identified in uveal melanoma, such as tumor basal diameter, tumor cell type, specific chromosome aberrations and a specific gene expression profile [19]. Immunologic determinants related to prognosis include HLA expression and lymphocyte and macrophage infiltration. Although it was thought that the presence of infiltrating antigen-presenting cells (APCs) would help to stimulate antitumor immune responses, current data suggests that the presence of infiltrating macrophages and $\mathrm{T}$ cells is associated with a worse survival $[9,15,20]$. The combined presence of infiltrating macrophages, lymphocytes and an increased expression of inflammation-related molecules (HLA class I and II) is known as the inflammatory phenotype of uveal malignant melanomas [21] (fig. 1).

\section{Cancer-Related Inflammation}

One wonders which biochemical pathways link inflammation and cancer. Genetic events may initiate the expression of inflammation-related molecules, leading to the recruitment of myelomonocytic cells and stimulation of angiogenesis [7]. Key orchestrators of the intrinsic pathway include specific transcription factors such as nuclear factor-kappa B and signal transducer activator of transcription-3, and inflammatory cytokines. Moreover, inflammation and cancer may have a mutual influence by contributing to the genetic instability of cancer cells. Uveal melanomas may acquire chromosomal defects as they grow, such as the loss of one copy of chromosome 3 (monosomy 3) or gain of (iso)chromosome 8q, further increasing the risk of metastatic death [22]. The inflammatory phenotype correlates with one specific genomic abnormality, i.e. the loss of one copy of chromosome 3 [21]. The exact genetic mechanisms involved in the pathogenesis of uveal melanoma remain unknown, but these events may include the activation of various types of oncogenes by mutation, or the inactivation of tumor-suppressor genes, initiating a pathophysiological mechanism 


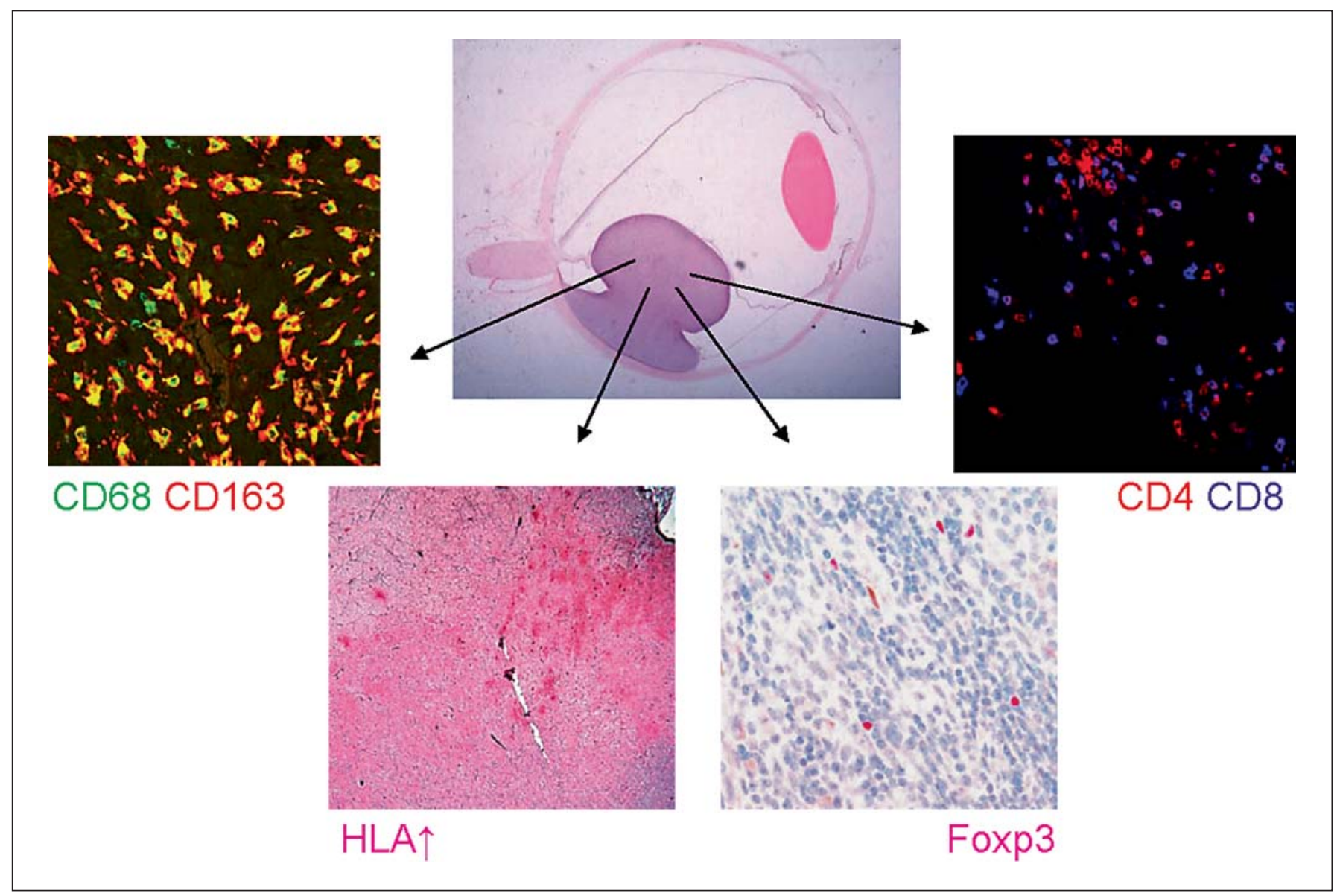

Fig. 1. Complex inflammatory phenotype in uveal melanoma, showing an inflammatory infiltrate consisting of CD68+CD163+ M2 macrophages, CD8+ T cells, CD4+ T cells, Foxp3+ regulatory T cells and increased HLA class I and II (HC10 is shown) expression of the uveal melanoma cells.

in which inflammation and infiltrating macrophages play an important role. For example, uveal melanoma cells which have lost one copy of chromosome 3 may produce inflammatory mediators, which recruit and activate various leukocytes, i.e. CD8+, CD4+ and Foxp3+ T cells, as well as macrophages. Activation of these infiltrating cells will result in more inflammatory mediators being produced and a cancer-related tumor-promoting inflammatory microenvironment being generated (fig. 2).

\section{Genome-Wide Microarray Analysis}

Gene-driven signals may activate intrinsic proinflammatory pathways that stimulate progression in cancer [23] and thus also in uveal melanoma. Using microarray gene expression profiling, unsupervised hier- archical cluster analysis resulted in two distinct entities of uveal melanoma, which are associated with chromosome 3 status [24]. When two gene signatures of 25 uveal melanomas were compared with respect to a 92 -month survival probability, gene expression profiling was found to be associated with survival [25]. Singh et al. [26] studied gene expression data of 27 uveal melanoma samples and showed that a poor patient survival was related to the expression of genes encoding the histocompatibility complex class I and class II, as well as other immune response genes (e.g. the nuclear factor of activated $\mathrm{T}$ cells, macrophage stimulating pseudogene 9). These findings suggest that survival is influenced by differences in inflammatory responses in the tumor. Further research is necessary to see whether the relevant genes are expressed by the microenvironment or by the tumor cells. 
Intrinsic pathway

Oncogene activation or loss of tumor suppression function

e.g. due to loss of a copy of chromosome 3 (monosomy 3 ) and/or other changes including gain of chromosome $8 q$ or isochromosome $8 q$

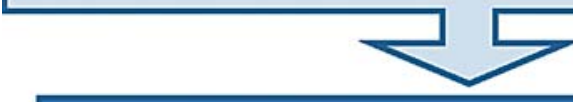

\section{Transcription factors activated in uveal melanoma cells}

Chemokines and cytokines

produced by uveal melanoma cells
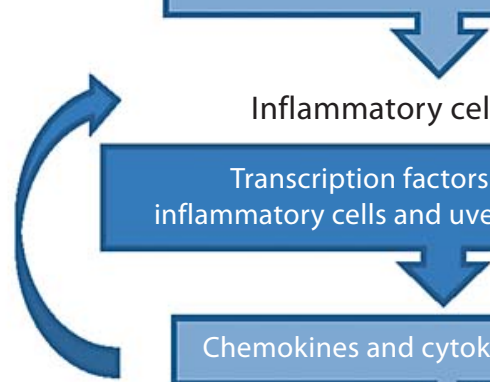

Inflammatory cells recruited

Transcription factors activated in inflammatory cells and uveal melanoma cells

Chemokines and cytokines produced
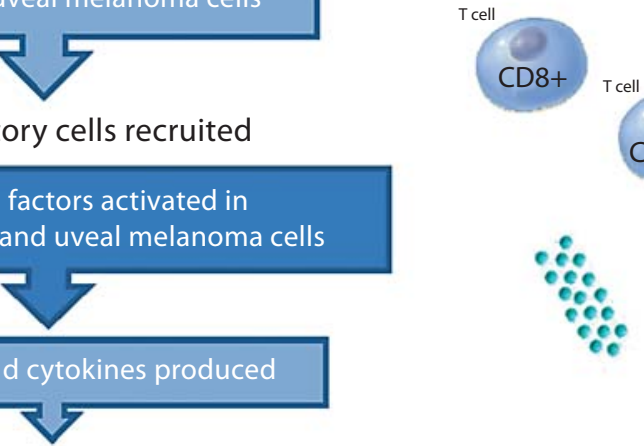

$<2$ $-3$ $+8 \mathrm{q} / \mathrm{i}(8 \mathrm{q})$

Cancer-related inflammation

- Angiogenesis

- Inhibition of adaptive immunity

Fig. 2. Cancer-related inflammation in uveal melanoma. An adaptation of the cancer-related inflammation theory focused on uveal melanoma (modified from Mantovani et al. [23]).

\section{Tumor-Promoting Inflammatory Microenvironment}

The orchestration of the myelomonocytic cell influx and function differentiation is an important element in pathways connecting inflammation and cancer. In uveal melanoma, there are several mechanisms whereby the tumor may take advantage of the inflammatory microenvironment. Instead of a strong antitumor response, the immune cells in the microenvironment, and in particular macrophages, probably adopt a trophic role during tumor progression. Uveal melanoma may actively recruit macrophages, with which they synergize to establish the proangiogenic, immunosuppressive, and thus prometastatic environment, which downregulates innate and adaptive immune responses.

Uveal Melanoma: The Inflammatory Microenvironment

\section{Promotion of Angiogenesis}

One very important determinant in uveal melanoma is angiogenesis. Uveal melanoma cells disseminate hematogenously, as there are extensive lymphatics within the orbit, but not inside the eye. In uveal melanoma, one can determine the MVD by counting the number of blood vessels per unit area in the most vascularized parts of the tumor ('hot spots') using anti-CD34 antibodies; this MVD is higher in tumors with epithelioid cells and is associated with a bad prognosis [27]. A higher vessel density is also associated with the number of tumor-infiltrating macrophages [15], which can be attributed to their proangiogenic M2-phenotype [18]. That macrophages may indeed play an important proangiogenic role in ocular tumors has been shown in an 
animal study in which removal of predominantly M2 macrophages in old mice by systemic injection of clodronate-containing liposomes directly reduced tumor outgrowth [28].

\section{Immunosuppression}

TAMs can lead to an immunosuppressive environment, as M2 macrophages produce anti-inflammatory cytokines such as interleukin (IL)-10 and transforming growth factor-beta (TGF- $\beta$ ). Using immunocytochemistry, the presence of TGF- $\beta$ was found in all of eleven human uveal melanoma stained with pan-TGF- $\beta$ or TGF$\beta_{2}$ antibody [29]. It remains unclear whether this detected TGF- $\beta$ is produced by the tumor cells or by the inflammatory cells. However, this specific microenvironment can modify $\mathrm{T}$ lymphocyte response, prevent $\mathrm{T}$ lymphocyte activation and proliferation and trigger the creation of suppressive and regulatory lymphocytes. The immunosuppressive role of TAMs has been suggested in a study where CD11b+ macrophage cells isolated from tumor-containing eyes of B6.Pl mice inhibited CD8+ CTL responses in vitro [30].

Besides their effect on CTLs, another link between macrophages and lymphocytes is indicated, as macrophages can profoundly affect Treg function, and vice versa. Culturing monocytes in the presence of Tregs resulted in differentiation into M2 macrophages and suppression of proinflammatory cytokines. Conversely, M2 macrophages may drive the conversion of naive $\mathrm{T}$ cells into adaptive Tregs and may also regulate their recruitment. IL-10 is an influential factor in this two-way interaction (reviewed by Biswas and Mantovani [31]). Tregs, as determined by nuclear Foxp3 staining, are present in a subset of uveal melanoma and have been associated with the extent of cyclooxygenase (COX)-2 expression [14]. COX-2 is a molecule involved in the COX-2/prostaglandin $\mathrm{E}_{2}$ $\left(\mathrm{PGE}_{2}\right)$ pathway, which is attributed to immune-modulating effects that strongly contribute to an immunosuppressive microenvironment in cancer. This indicates that part of the T cells present in uveal melanoma should be able to suppress local immunity. Moreover, the number of CD68+CD163+ M2 macrophages was strongly associated with the number of infiltrating Foxp3+ Tregs (unpubl. data). Lymphocytes recovered from six ocular melanomas all had the capacity to lyse tumor cells [32]. This cytotoxic activity was revealed when these lymphocytes were cultured in the presence of exogenous IL-2, indicating that lymphocytes with the potential to kill melanoma cells accumulate in uveal melanomas. These nonspecific lymphocytes that thus can be activated are probably sup- pressed in the in situ microenvironment. In this way, a growing uveal melanoma orchestrates a web of distinct but integrated suppressive activities.

\section{Antigen Presentation on Local APCs}

The activation and function of APCs is known to vary considerably based on the location of these cells. Sufficient antigen presentation is necessary to obtain efficient T cell priming. The ability of APCs in the microenvironment of uveal melanomas to effectively present antigen or activate $\mathrm{T}$ cells was determined by analyzing the expression of CD40 and CD83 on macrophages and dendritic cells (DCs) [33]. CD40, necessary for T cell stimulation, was present on pigmented macrophages in 7 out of 10 tested cases of uveal melanoma. In contrast, CD40 was not present on DCs. Moreover, CD83, a marker of mature DCs, was present on a few cells in only one tumor and completely absent in the remaining tumors. The absence of mature APC phenotypes in the tumor may affect the ability of T cells to mount an antitumor response in uveal melanoma.

\section{The Role of Soluble Factors}

The uveal melanoma microenvironment includes soluble components, e.g. cytokines that may be derived from either neoplastic or nonneoplastic cells. Cytokines and their receptors constitute a large family of molecules that control the trafficking of immune cells during their development. For example, TAMs originate as blood monocytes recruited from the tumor vasculature by tumor-derived signals. Inflammation is not only localized in the tumor itself, as uveal melanoma-containing eyes often carry increased levels of inflammation-related cytokines in their aqueous humor, e.g. IL-6, MCP-1, macrophage migration inhibitory factor, bFGF, RANTES, GM-CSF, VEGF, ICAM-1, VCAM, and IP-10 [34]. Moreover, this study demonstrated that the presence of these inflammatory cytokines was independent of the macrophage population present in the tumor.

Several in vitro studies of uveal melanoma showed a range of important factors. In one study, melanoma cell lines expressed IL-2R and IL-15R, while tumor-infiltrating lymphocytes and macrophages produced IL-2 and IL15 that stimulated tumor cell proliferation [35]. Soluble factors secreted by macrophages influence the production of the melanoma inhibitory activity (MIA) of uveal 
melanoma cells [36]. MIA is known to inhibit tumor cell attachment to the extracellular matrix enhancing their invasive potential. Production of MIA by tumor cells increased when macrophage-conditioned medium was added to human uveal melanoma cell lines.

In turn, tumor cells may influence their interaction with macrophages by promoting an M2-like polarization. Among the factors that can promote polarization of M2 macrophages are VEGF, M-CSF, TGF- $\beta$, IL-6, IL-10 and $\mathrm{PGE}_{2}$ [37]. Uveal melanoma cell lines commonly express angiogenic as well as immunosuppressive factors, including VEGF, TGF- $\beta_{2}$, the secreted form of IL- 1 receptor antagonist (sIL-1ra), IL-6, IL-8 and IL-10 [38]. However, expression varied between cell lines and cytokine production was not necessarily confirmed by ELISA. Endothelial monocyte-activating polypeptide (EMAP)-II is a chemotactic cytokine which has an effect on macrophages. The colocalization of EMAP-II and macrophages was seen in serial sections of 25 primary uveal melanoma, indicating that macrophages had accumulated at sites with EMAP-II expression [39]. Macrophage migration inhibitory factor, a cytokine that produces an immediate inhibition of NK cell-mediated lytic activity, is produced by uveal melanoma cell lines [40]. This NK-inhibiting immune privilege contributes to the growth and metastasis of ocular melanomas by affecting cytolysis of uveal melanoma target cells.

When cytokine expression was determined by mRNA analysis in 16 primary uveal melanomas and compared to healthy choroids, significant variability in expression was seen - TGF- $\alpha$ was present in 15 and IL-2 in 14 of the 16 tumors. Other mRNAs of cytokines were rarer - interferon-gamma (IFN- $\gamma$ ) was only seen in 4 cases, TNF $\alpha$ in 1 and IL-4 was not found at all [41]. This specific cytokine profile showed no association with infiltrating lymphocytes or macrophages, as detected by flow cytometry. Interestingly, IFN- $\gamma$-mRNA expression was significantly associated with the development of metastasis. IFN- $\gamma$ can upregulate the expression in uveal melanoma cells of two immunoinhibitory molecules, indoleamine 2,3-dioxygenase (IDO) and programmed cell death-1 (reviewed by Niederkorn [42]). IFN- $\gamma$ inducible IDO upregulation by primary uveal melanoma may generate a local immune-privileged microenvironment to promote an escape from $\mathrm{T}$ cell-mediated immune surveillance. However, one immunohistochemical study demonstrated that programmed cell death-1 was not expressed by five primary uveal melanomas in situ [43], while another study on primary uveal melanoma showed that they also did not express IDO [44]. Therefore, in- stead of a direct release of IDO, TGF- $\beta$ or IL-10 by uveal melanoma cells, the TIL including TAMs may help by producing these cytokines.

The 'cross-talk' between uveal melanoma tumor cells and macrophages was seen in experiments where uveal melanoma and a monocyte cell line (28SC) were cultured in each other's conditioned medium $[45,46]$. 28SC incubated in melanoma-conditioned medium caused higher upregulation of IL- 6 and VEGF than did uveal melanoma cells incubated in a monocyte-conditioned medium, while $\mathrm{PGE}_{2}$ remained undetectable. Furthermore, uveal melanoma soluble factors have been shown to have an inhibitory effect on the cytotoxic or antitumor activity of macrophages as melanoma-conditioned medium inhibited nitric oxide production by macrophages [47]. This is an example of uveal melanoma-induced suppression of the polarized M1-tumoricidal function. A shift in macrophage polarization was induced in a xenograft experimental uveal melanoma mouse model when inhibiting IL-1 with an antagonist (IL-1ra) resulted in growth inhibition of MUM2B and OCM1 tumors [48]. After this IL-1ra treatment, TAMs showed a lower expression of M2 markers (such as arginase and CD206), but a higher expression of M1 markers (such as IL-12(p40) and CXCL10).

\section{Macrophage-Influx after Therapy}

Treatment of the primary uveal melanoma may affect leukocyte influx. There are many options available for the treatment of uveal melanoma, such as enucleation, plaque radiotherapy (e.g. episcleral ruthenium-106 application), proton beam radiotherapy and transpupillary thermotherapy (reviewed by Papastefanou and Cohen [49]). Moderate to high numbers of tumor-infiltrating macrophages were present in the majority of irradiated melanomas. Following brachytherapy with ruthenium plaques, the central tumor area contained melanoma cells with major signs of radiation-related changes, and included variable numbers of lymphocytes and macrophages [50]. These intratumoral macrophages often carried pigment and are called melanophages. In another study, two of the most prominent findings within tumors following ruthenium plaque therapy were tumor cell necrosis and an accumulation of pigmented macrophages [51]. Local treatment with thermotherapy also stimulated the influx of macrophages [52]. After (experimental) transscleral thermotherapy (TSTT), a high density of CD68+ macrophages was found at the borders of treated 
spots [53]. Even at a 10-year follow-up examination of a patient with macular uveal melanoma treated with proton beam irradiation, the pigmented choroidal mass consisted of spindle cells and a large number of pigment-laden macrophages [54]. When primarily enucleated eyes were compared to secondarily enucleated eyes after brachytherapy in a case-control analysis of 34 matched pairs, significantly more necrosis and a lower MVD was observed in the melanomas of the brachytherapy-treated group [55]. However, the macrophages were similarly distributed in both groups, but only associated with the MVD in the primarily enucleated tumors. Therefore, reduced MVD after brachytherapy cannot be attributed to different numbers of TAMs or differences in cell infiltration in the nonnecrotic areas of the tumor. In support of these observations, further analysis of the TSTT-treated tumors revealed that the macrophages at the border of the TSTT-treated areas were both CD68 and CD163 positive and thus typical M2 macrophages [53]. Following treatment, the most important role of macrophages in tissue repair and/or phagocytosis may be to clear damaged tumor cells, and not their proangiogenic function.

Local tumor treatment thus affects the influx of scavenger cells that help to remove tumor cells. Recent evidence suggests that before irradiation macrophages preferentially migrate to the tumor through the choroid and after irradiation through the sclera [56]. Pigmented episcleral deposits have been observed in most eyes after brachytherapy and it has been observed that these deposits are related to transsclerally migrating macrophages carrying pigment debris. The more the tumor has shrunk by 3 years after brachytherapy, the higher the number of pigmented episcleral deposits [57]. The influence of these routes (and function of macrophages) on tumor progression and regression should be further studied in vivo.

\section{Conclusions}

Uveal melanoma development and expansion appear to be dependent on multiple signals mediated by the inflammatory microenvironment. Besides the neoplastic uveal melanoma cells, there are numerous other actors (nonmalignant cells) present on the stage, including lymphocytes and macrophages. Also cytokines and chemokines have an important role in this network of cells within the microenvironment. Inside this complex microenvironment, uveal melanomas have adapted in such a way that they take control of the local host immune response through influencing the relative distribution and activation state of these various cell subpopulations. With regard to treatment, the complex network of different infiltrating cells should be addressed instead of focusing on the tumor cells alone. The unique interplay between tumor cells, immune cells and cytokines suggests that immunomodulation may prove to be a useful therapy in the treatment of uveal melanoma. Studies that better characterize the dynamic relationship between these three players will be valuable not only in understanding the pathophysiologic mechanisms of tumor growth and immune evasion, but also in devising new therapies. In situ immune cell traffic, e.g. by life imaging, can be instrumental in understanding the initiation of adaptive immunity and will certainly reveal novel features in uveal melanoma-related inflammation.

\section{Acknowledgements}

This work was supported by grants from the Board of Directors of the Leiden University Medical Center $\mathrm{MD} / \mathrm{PhD}$ trajectory (recipient: I.H.G.B), Stichting Nederlands Oogheelkundig Onderzoek, Rotterdamse Stichting Blindenbelangen and Landelijke Stichting voor Blinden en Slechtzienden. We thank Dr. Nisha Nagarkatti-Gude and Dr. Moniek Heusinkveld for critically reading the manuscript.
References

J Innate Immun 2012;4:454-462
Singh AD, Turell ME, Topham AK: Uveal melanoma: trends in incidence, treatment, and survival. Ophthalmology 2011;118: 1881-1885.

-2 Kujala E, Makitie T, Kivela T: Very long-term prognosis of patients with malignant uveal melanoma. Invest Ophthalmol Vis Sci 2003; 44:4651-4659.

- 3 Rietschel P, Panageas KS, Hanlon C, Patel A, Abramson DH, Chapman PB: Variates of survival in metastatic uveal melanoma. J Clin Oncol 2005;23:8076-8080

\footnotetext{
4 Damato B, Coupland SE: Managing patients with ocular melanoma: state of the art. Clin Experiment Ophthalmol 2008;36:589-590.

5 Skalicky SE, Holt PE, Giblin M, Taylor S, Conway RM: Australian Cancer Network clinical practice guidelines for the management of ocular and periocular melanoma: an evidence-based literature analysis. Clin Experiment Ophthalmol 2008;36:646-658.
} 
6 McKenna KC, Chen PW: Influence of immune privilege on ocular tumor development. Ocul Immunol Inflamm 2010;18:8090.

7 Colotta F, Allavena P, Sica A, Garlanda C, Mantovani A: Cancer-related inflammation, the seventh hallmark of cancer: links to genetic instability. Carcinogenesis 2009;30: 1073-1081.

8 Cavallo F, De Giovanni C, Nanni P, Forni G, Lollini PL: 2011: the immune hallmarks of cancer. Cancer Immunol Immunother 2011; 60:319-326.

$>9$ de la Cruz PO Jr, Specht CS, McLean IW: Lymphocytic infiltration in uveal malignant melanoma. Cancer 1990;65:112-115.

10 Meecham WJ, Char DH, Kaleta-Michaels S: Infiltrating lymphocytes and antigen expression in uveal melanoma. Ophthalmic Res 1992;24:20-26.

-11 De Waard-Siebinga I, Hilders CG, Hansen BE, van Delft JL, Jager MJ: HLA expression and tumor-infiltrating immune cells in uveal melanoma. Graefes Arch Clin Exp Ophthalmol 1996;234:34-42.

-12 Durie FH, Campbell AM, Lee WR, Damato BE: Analysis of lymphocytic infiltration in uveal melanoma. Invest Ophthalmol Vis Sci 1990;31:2106-2110.

13 Lagouros E, Salomao D, Thorland E, Hodge DO, Vile R, Pulido JS: Infiltrative T regulatory cells in enucleated uveal melanomas. Trans Am Ophthalmol Soc 2009; 107:223228.

14 Mougiakakos D, Johansson CC, Trocme E, All-Ericsson C, Economou MA, Larsson O, Seregard S, Kiessling R: Intratumoral forkhead box P3-positive regulatory $\mathrm{T}$ cells predict poor survival in cyclooxygenase-2-positive uveal melanoma. Cancer 2010;116: 2224-2233.

15 Makitie T, Summanen P, Tarkkanen A, Kivela $\mathrm{T}$ : Tumor-infiltrating macrophages (CD68(+) cells) and prognosis in malignant uveal melanoma. Invest Ophthalmol Vis Sci 2001;42:1414-1421.

16 Anastassiou G, Coupland SE, Stang A, Boeloeni R, Schilling H, Bornfeld $\mathrm{N}$ : Expression of Fas and Fas ligand in uveal melanoma: biological implication and prognostic value. J Pathol 2001;194:466-472.

-17 Schmidt T, Carmeliet P: Blood-vessel formation: bridges that guide and unite. Nature 2010;465:697-699.

18 Bronkhorst IH, Ly LV, Jordanova ES, Vrolijk J, Versluis M, Luyten GP, Jager MJ: Detection of M2-macrophages in uveal melanoma and relation with survival. Invest Ophthalmol Vis Sci 2011;52:643-650.

19 Laver NV, McLaughlin ME, Duker JS: Ocular melanoma. Arch Pathol Lab Med 2010; 134:1778-1784.

-20 Whelchel JC, Farah SE, McLean IW, Burnier MN: Immunohistochemistry of infiltrating lymphocytes in uveal malignant melanoma. Invest Ophthalmol Vis Sci 1993;34:26032606.
21 Maat W, Ly LV, Jordanova ES, WolffRouendaal D, Schalij-Delfos NE, Jager MJ: Monosomy of chromosome 3 and an inflammatory phenotype occur together in uveal melanoma. Invest Ophthalmol Vis Sci 2008; 49:505-510.

22 Kilic E, Naus NC, van Gils W, Klaver CC, van Til ME, Verbiest MM, Stijnen T, Mooy CM, Paridaens D, Beverloo HB, Luyten GP, de Klein A: Concurrent loss of chromosome arm $1 \mathrm{p}$ and chromosome 3 predicts a decreased disease-free survival in uveal melanoma patients. Invest Ophthalmol Vis Sci 2005;46:2253-2257.

23 Mantovani A, Allavena P, Sica A, Balkwill F: Cancer-related inflammation. Nature 2008; 454:436-444.

24 Tschentscher F, Husing J, Holter T, Kruse E, Dresen IG, Jockel KH, Anastassiou G, Schilling $\mathrm{H}$, Bornfeld $\mathrm{N}$, Horsthemke B, Lohmann DR, Zeschnigk M: Tumor classification based on gene expression profiling shows that uveal melanomas with and without monosomy 3 represent two distinct entities. Cancer Res 2003;63:2578-2584.

25 Onken MD, Worley LA, Ehlers JP, Harbour JW: Gene expression profiling in uveal melanoma reveals two molecular classes and predicts metastatic death. Cancer Res 2004;64: 7205-7209.

26 Singh AD, Sisley K, Xu Y, Li J, Faber P, Plummer SJ, Mudhar HS, Rennie IG, Kessler PM, Casey G, Williams BG: Reduced expression of autotaxin predicts survival in uveal melanoma. Br J Ophthalmol 2007;91:1385-1392.

27 Makitie T, Summanen P, Tarkkanen A, Kivela $\mathrm{T}$ : Microvascular density in predicting survival of patients with choroidal and ciliary body melanoma. Invest Ophthalmol Vis Sci 1999;40:2471-2480.

28 Ly LV, Baghat A, Versluis M, Jordanova ES, Luyten GP, van Rooijen N, van Hall T, van der Velden PA, Jager MJ: In aged mice, outgrowth of intraocular melanoma depends on proangiogenic M2-type macrophages. J Immunol 2010;185:3481-3488.

29 Esser P, Grisanti S, Bartz-Schmidt K: TGFbeta in uveal melanoma. Microsc Res Tech 2001;52:396-400.

- 30 McKenna KC, Kapp JA: Accumulation of immunosuppressive CD11b+ myeloid cells correlates with the failure to prevent tumor growth in the anterior chamber of the eye. J Immunol 2006;177:1599-1608.

31 Biswas SK, Mantovani A: Macrophage plasticity and interaction with lymphocyte subsets: cancer as a paradigm. Nat Immunol 2010;11:889-896.

- 32 Ksander BR, Geer DC, Chen PW, Salgaller ML, Rubsamen P, Murray TG: Uveal melanomas contain antigenically specific and non-specific infiltrating lymphocytes. Curr Eye Res 1998;17:165-173.
33 Polak ME, Borthwick NJ, Johnson P, Hungerford JL, Higgins B, Di Palma S, Jager MJ, Cree IA: Presence and phenotype of dendritic cells in uveal melanoma. Br J Ophthalmol 2007;91:971-976.

-34 Ly LV, Bronkhorst IH, van Beelen E, Vrolijk J, Taylor AW, Versluis M, Luyten GP, Jager MJ: Inflammatory cytokines in eyes with uveal melanoma and relation with macrophage infiltration. Invest Ophthalmol Vis Sci 2010;51:5445-5451.

- 35 He YG, Mayhew E, Mellon J, Niederkorn JY: Expression and possible function of IL-2 and IL-15 receptors on human uveal melanoma cells. Invest Ophthalmol Vis Sci 2004;45: 4240-4246.

36 Callejo SA, Marshall JC, Cools-Lartigue J, Saraiva VS, Burnier MN Jr: Macrophage-derived soluble factor enhances melanoma inhibitory activity expression by uveal melanoma cells in vitro. Melanoma Res 2004;14: 91-95.

37 Gottfried E, Kreutz M, Mackensen A: Tumor-induced modulation of dendritic cell function. Cytokine Growth Factor Rev 2008; 19:65-77.

38 Ijland SA, Jager MJ, Heijdra BM, Westphal JR, Peek R: Expression of angiogenic and immunosuppressive factors by uveal melanoma cell lines. Melanoma Res 1999;9:445450.

39 Clarijs R, Schalkwijk L, Ruiter DJ, de Waal RM: EMAP-II expression is associated with macrophage accumulation in primary uveal melanoma. Invest Ophthalmol Vis Sci 2003; 44:1801-1806.

40 Repp AC, Mayhew ES, Apte S, Niederkorn JY: Human uveal melanoma cells produce macrophage migration-inhibitory factor to prevent lysis by NK cells. J Immunol 2000; 165:710-715.

41 Filer RS, Song JC, Char DH, Kaleta-Michaels S: Uveal melanoma cytokines (in German). Klin Monbl Augenheilkd 1993;202:174-179.

42 Niederkorn JY: Immune escape mechanisms of intraocular tumors. Prog Retin Eye Res 2009;28:329-347.

43 Yang W, Chen PW, Li H, Alizadeh H, Niederkorn JY: PD-L1: PD-1 interaction contributes to the functional suppression of T-cell responses to human uveal melanoma cells in vitro. Invest Ophthalmol Vis Sci 2008;49: 2518-2525.

44 Chen PW, Mellon JK, Mayhew E, Wang S, He YG, Hogan N, Niederkorn JY: Uveal melanoma expression of indoleamine 2,3-deoxygenase: establishment of an immune privileged environment by tryptophan depletion. Exp Eye Res 2007;85:617-625.

45 Cools-Lartigue J, Marshall JC, Caissie AL, Saraiva VS, Burnier MN Jr: Secretion of interleukin- 6 and prostaglandin E2 during uveal melanoma-monocyte in vitro interactions. Exp Eye Res 2004;79:451-454. 
\46 Cools-Lartigue J, Marshall JC, Caissie AL, Saraiva VS, Burnier MN Jr: Secretion of hepatocyte growth factor and vascular endothelial growth factor during uveal melanoma-monocyte in vitro interactions. Melanoma Res 2005;15:141-145.

-47 Marshall JC, Caissie AL, Cruess SR, CoolsLartigue J, Burnier MN Jr: The effects of a cyclooxygenase-2 (COX-2) expression and inhibition on human uveal melanoma cell proliferation and macrophage nitric oxide production. J Carcinog 2007;6:17.

48 Triozzi PL, Aldrich W, Singh A: Effects of interleukin-1 receptor antagonist on tumor stroma in experimental uveal melanoma. Invest Ophthalmol Vis Sci 2011;52:5529-5535.

49 Papastefanou VP, Cohen VM: Uveal melanoma. J Skin Cancer 2011;2011:1-13.
Schilling H, Sehu KW, Lee WR: A histologic study (including DNA quantification and Ki-67 labeling index) in uveal melanomas after brachytherapy with ruthenium plaques. Invest Ophthalmol Vis Sci 1997;38:20812092.

51 Messmer E, Bornfeld N, Foerster M, Schilling $\mathrm{H}$, Wessing A: Histopathologic findings in eyes treated with a ruthenium plaque for uveal melanoma. Graefes Arch Clin Exp Ophthalmol 1992;230:391-396.

52 Schurmans LR, Blom DJ, De Waard-Siebinga I, Keunen JE, Prause JU, Jager MJ: Effects of transpupillary thermotherapy on immunological parameters and apoptosis in a case of primary uveal melanoma. Melanoma Res 1999;9:297-302.

53 Dennaoui J, Bronkhorst IH, Ly LV, de WolffRouendaal D, Keunen JE, Schalij-Delfos NE, Jager MJ: Changes in immunological markers and influx of macrophages following trans-scleral thermotherapy of uveal melanoma. Acta Ophthalmol 2011;89:268-273.
54 Young LH, Gragoudas ES: Macular uveal melanoma treated with proton beam irradiation. 10-year follow-up observation with histopathologic correlation. Retina 1994;14:4346.

55 Toivonen P, Makitie T, Kujala E, Kivela T: Macrophages and microcirculation in regressed and partially regressed irradiated choroidal and ciliary body melanomas. Curr Eye Res 2003;27:237-245.

56 Toivonen P, Kivelä T: Infiltrating macrophages in extratumoural tissues after brachytherapy of uveal melanoma. Acta Ophthalmol 2010, E-pub ahead of print.

57 Toivonen P, Kivelä T: Pigmented episcleral deposits after brachytherapy of uveal melanoma. Ophthalmology 2006;113:865-873. 